\title{
Um Projeto Republicano para o Povo Brasileiro: A Utopia Possível no Pensamento Social e Educacional de Celso Furtado e Darcy Ribeiro
}

\author{
A Republican Project for the Brazilian People: The Possible Utopia in the Social and \\ Educational Thought of Celso Furtado and Darcy Ribeiro
}

\author{
Lia Ciomar Macedo de Faria \\ Universidade do Estado do Rio de Janeiro \\ liafolia11@gmail.com \\ Lincoln de Araújo Santos \\ Universidade do Estado do Rio de Janeiro \\ liarsan@gmail.com
}

\begin{abstract}
Resumo Este Da linhagem de intelectuais que problematizaram a formação do povo brasileiro, dois personagens de nossa república se destacam, não só pelas obras que deixaram, mas porque experimentaram concomitante às suas capacidades de formulação teórica, o exercício da política, no enfrentamento do poder do Estado, em governos datados, são eles Celso Furtado e Darcy Ribeiro. O objetivo deste artigo é o de articular o pensamento social e educacional de Celso Furtado e de Darcy Riberio buscando ressaltar os ideários de cada um sobre o projeto nacional de desenvolvimento econômico e social, muito presente entre os anos de 1950-1960 no Brasil.
\end{abstract}

Palavras Chaves: Celso Furtado, Darcy Ribeiro, pensamento social brasileiro, intelectual orgânico.

\begin{abstract}
From the lineage of intellectuals who questioned the formation of the Brazilian people, two characters from our republic stand out, not only for the works they left, but because they experimented with their theoretical formulation skills, the exercise of politics, in confronting the power of the State, in dated governments, they are Celso Furtado and Darcy Ribeiro. The aim of this article is to articulate the social and educational thinking of Celso Furtado and Darcy Riberio, seeking to highlight the ideas of each one about the national project of economic and social development, very present between the years 1950-1960 in Brazil.
\end{abstract}

Keywords: Celso Furtado, Darcy Ribeiro, Brazilian social thought, organic intellectual. 


\section{Introdução}

O século XX no Brasil pautou uma geração de intelectuais que influenciaram o pensamento social brasileiro. Das ciências sociais à literatura, tivemos um campo de reflexão sobre os problemas nacionais, o retrato de seu povo e de suas antropologias e sociabilidades, além das descrições plurais dos cenários cruéis da escravidão e das relações de produção que estruturalmente definiram os caminhos de percepção sobre o país.

A questão central sobre a construção do Brasil enquanto nação perpassou os anos do final do império e o início da república. A busca dos sentidos que viessem a justificar a formação e as matrizes étnicas e regionais marcou a trajetória de um povo que não se ajustava às interpretações ou modelos civilizatórios predeterminados pelos estudos eurocêntricos.

Desta forma, Oliveira Vianna, em sua obra, Populações Meridionais do Brasil (1920), descreveu os processos de formação dos grupos sociais que se constituíram em geografias diversificadas, de comunidades que se forjaram considerando o litoral e o interior do país. Na obra, Os Sertões (1902), Euclides da Cunha também propôs uma leitura das regionalidades, da cultura que emanava das forças de trabalho, do controle da terra, do sertanejo em conflito permanente com as imposições da lógica política e econômica.

O marco de inserção do capitalismo industrial no Brasil, enquanto projeto explícito a partir de 1930, ampliou o crivo de reflexão sobre o país, onde a passagem do rural para o urbano, da economia agroexportadora para a produção industrial conceberam análises significativas sobre a questão brasileira. As obras de Caio Prado Jr. e Florestan Fernandes são atuais para percebermos as contradições do caminho civilizatório brasileiro, nos conflitos de classe e dos períodos onde as relações materiais de produção determinaram em parte a nossa história social.

Desta linhagem de intelectuais que problematizaram a formação do povo brasileiro, dois personagens de nossa república se destacam, não só pelas obras que deixaram, mas porque experimentaram concomitante às suas capacidades de formulação teórica, o exercício da política, no enfrentamento do poder do Estado, em governos datados. A relevância de Celso Furtado e Darcy Ribeiro ainda repercute com toda a vitalidade e fôlego, numa conjuntura de país onde os valores republicanos e da 
humanidade, concebidos em séculos passados, estão sendo atacados e abandonados pela onda neoconservadora mundial e por parte das elites dirigentes do país.

Ambos compõem um coletivo de intelectuais dos anos 1960, surgindo num contexto histórico de crises institucionais da república brasileira, do ambiente internacional da guerra-fria, porém compondo suas formulações teóricas nos campos da economia política, da antropologia cultural e da educação vinculadas às questões do terceiro mundo e do desenvolvimento social e econômico. Segundo Ridenti (2003: 188), são de uma intelectualidade produtora de direitos da esfera ideológica onde os problemas epistemológicos da identidade nacional e política do povo brasileiro, buscando ao mesmo tempo, a natureza das questões econômicas e sociais do país e as rupturas com o subdesenvolvimento.

Para que possamos buscar maior aproximação na análise desses dois atores republicanos, entendemos que a compreensão sobre o intelectual orgânico gramsciano, nos auxilia na tarefa de traçarmos um sentido histórico na reflexão entre os operadores do Estado, aqueles que governam e, ao mesmo tempo, aqueles que atuam nas funções de pensadores críticos da realidade social. O intelectual orgânico é o sujeito que pondera sobre o projeto político de seu tempo, sendo este institucional, no âmbito das organizações da sociedade civil ou do Estado. Observa o mundo, se vê nele e lhe oferece sentidos e interpretações. Gramsci, afirma que todo grupamento social cria para si, organicamente, intelectuais que lhe darão consciência de sua própria existência e atuação. Tal perspectiva nos esclarece sobre as dimensões políticas e sociais de Celso Furtado e Darcy Ribeiro e todos aqueles que conviveram com eles em redes de reciprocidade. (GRAMSCI, 2006: 21)

Um dos propósitos deste artigo é o de se articular o pensamento social e educacional de Celso Furtado e de Darcy Riberio buscando ressaltar os ideários de cada um sobre o projeto nacional de desenvolvimento econômico e social, muito presente entre os anos de 1950-1960 no Brasil, bem como destacar a utopia brasileira contida em suas obras. Nosso desafio é também o de compreender a importância histórica e política desses intelectuais na função da educação e de seu planejamento no contexto do desenvolvimento social e de luta pela soberania política do povo brasileiro.

\section{Personagens forjados numa República contraditória}


Celso Furtado e Darcy Ribeiro nasceram na década de $1920^{1}$, num período de efervescência republicana onde irrompem uma série de acontecimentos que demarcaram um complexo período da sociedade brasileira: A Semana de Arte Moderna e a fundação do Partido Comunista Brasileiro-PCB, em 1922; a organização da Associação Brasileira de Educação-ABE, uma das responsáveis pela disseminação do escolanovismo e do pensamento liberal na educação brasileira, em 1924, e as reformas educacionais regionais ocorridas em São Paulo, Rio de Janeiro, Minas Gerais, Bahia, Ceará e Pernambuco. Tais reformas uniram outro campo de intelectuais-educadores, destacando-se Anísio Teixeira, Fernando de Azevedo, Lourenço Filho, Sampaio Dória, dentre outros. As crises institucionais dos governos de Artur Bernardes (1922-1926) e Washington Luís (1926-1930) representaram as fragilidades da política quanto do cumprimento da democracia liberal republicana e de como se concebeu um viés de poder autoritário e de uma mentalidade anticidadã, de controle e criminalização dos movimentos sociais que emergiram neste tempo.

Um século depois, as ciências sociais no Brasil e sua extensa produção de pesquisa historiográfica, ainda encontrarão fôlego para buscar nesta década emblemática dos anos 1920, fatos, personagens e processos sociais que se manifestaram e que encontram ressonância até o tempo presente, em plena crise da democracia e da república brasileira tais como o Cangaço no Nordeste, um contraponto ao ideário urbano-liberal ao Tenentismo, expressões que também emergem neste período. No campo educacional, Roquette-Pinto fundou, em 1923, a Rádio Sociedade do Rio de Janeiro, pioneira e com dedicação específica na difusão da educação e a cultura universal e brasileira. A crise econômica de 1929 desencadeou mudanças políticas no país, inaugurando o protagonismo de Vargas e o avanço da industrialização.

Para Vasconcellos (1999), Darcy Ribeiro foi o melhor discípulo de RoquettePinto, sinal que evidencia que o ideário educacional dos anos 1920 e seus personagens auxiliaram em sua formação. No pensamento e obra de Celso Furtado e a centralidade dos fatos de 1929 concentram os marcos de análise do capitalismo periférico e de suas consequências no território latino-americano, em especial o tema é tradado na quinta

\footnotetext{
${ }^{1}$ Celebramos em 2020, o centenário de nascimento de Celso Furtado e de Florestan Fernandes. Em 2022 comemoraremos o centenário de nascimento de Darcy Ribeiro, de Leonel Brizola, da Semana de Arte Moderna e de fundação do Partido Comunista Brasileiro-PCB.
} 
parte do clássico da historiografia econômica brasileira, Formação Econômica do Brasil - Economia de Transição para Um Sistema Industrial ${ }^{2}$.

Estes dois personagens tiveram experiências singulares em suas trajetórias, em ambientes políticos em que transitavam, convivendo em grupos diferentes e também em seus estudos e proposições sobre o Brasil, mas entendemos que sofreram influências da conjuntura que nasceram em tempos conturbados de uma república que se fez incompleta e contraditória.

Celso Furtado Ingressou no curso de direito da Universidade do Brasil em 1944 e no doutorado em economia em Paris, no período de 1946 a 1948, o que lhe fez alargar os estudos e sua formação acadêmica. Aos 23 anos, integrou-se à função pública, em Pernambuco, seguindo a tradição familiar, de seu avô e do pai, quando foi despertado para os estudos sobre os problemas sociais brasileiros.

Recebeu influências de pensadores que contribuíram em seus estudos sobre a história econômica do Brasil e da América Latina. Na juventude, o acesso à obra, Casa Grande \& Senzala, de Gilberto Freyre (1933), trouxe-lhe o impacto da formação de uma sociedade desigual e complexa. Apropriou-se dos conhecimentos sobre a sociologia do conhecimento reconhecendo a importância dos estudos históricos a partir do pensamento de Karl Mannheim. Há evidências nos estudos de Celso Furtado sobre o método científico em Marx, o lhe ajudou a fortalecer suas ideias, principalmente quando se percebe nas díades das relações de produção e trabalho das sociedades brasileira, latino-americana e no mundo, principalmente em suas análises sobre as relações de dependência econômica entre o centro-periferia, as díades do desenvolvimentosubdesenvolvimento, etc.

A obra de J. M. Keynes foi marcante para que Furtado percebesse o papel do Estado capitalista num contexto de crise, onde o planejamento, os vetores para o desenvolvimento econômico não poderiam prescindir das instituições públicas e de suas

\footnotetext{
${ }^{2}$ No artigo publicado na Folha de São Paulo de 1999, Darcy Ribeiro, o útero do povo, o professor Gilberto Vasconcellos articulou comparativamente a figura de Darcy Ribeiro com intelectuais e personagens da cultura brasileira, dando relevância à sua vida intelectual e política. Num trecho do artigo, fala sobre o Darcy antropólogo: "Revolução não é sinônimo de violência nem insurreição armada. Etnólogo das civilizações quis escrever a história crítica da tecnologia que Karl Marx reivindicara em "O Capital". Na obra de Celso Furtado, 1929 é referência permanente em seus estudos e reflexões: "A industrialização brasileira, ocorrida a partir dos anos 1930, deu-se sem modificações estruturais significativas, independentemente da existência de uma política de desenvolvimento. O ponto de partida foi a crise do sistema primário-exportador, crise que envolveu o Estado, porquanto este vinha intervindo amplamente na comercialização do principal produto de exportação, café. Assegurando preços altos a esse produto, o governo estimulou a superprodução, agravando a crise gerada no plano internacional pelo crasch financeiro de 1929" (FURTADO, 2014: 425).
} 
inserções na sociedade, de forma a organizá-la para a promoção do desenvolvimento, concomitante ao bem-estar social. As análises que realizou sobre a crise do capitalismo em 1929 e os impactos históricos e econômicos da Revolução de 1930 foram aspectos singulares em sua leitura sobre o Brasil, seus processos de industrialização e desenvolvimento (FURTADO, 2014).

O ideário cepalino, sob influência de companheiros economistas e cientistas sociais, de não só identificar o caráter da dependência entre o capitalismo industrial desenvolvido na Europa e América do Norte e os países periféricos subordinados aos processos de exploração, presentes na América Latina e África, fizeram com que Furtado percebesse a necessidade política de conceber um projeto de autonomia para o desenvolvimento dessas regiões.

Darcy Ribeiro, aos dezessete anos, saiu de sua cidade natal, Montes Claros, Minas Gerais para que, em Belo Horizonte ingressasse no Curso de Medicina, atendendo principalmente a um pedido materno. No ambiente universitário, deparou-se com um campo de conhecimento que lhe atraiu em disciplinas tais como a filosofia e a história. Neste período, conheceu um grupo de jovens que futuramente seriam reconhecidos como intelectuais mineiros, por conta de suas obras no jornalismo e literatura, dentre eles, Hélio Peregrino, Fernando Sabino, Otto Lara Resende e Paulo Mendes Campos. Em 1944 vai para São Paulo, ingressando na Escola Livre de Sociologia e Política-ELSP.

Em São Paulo, conviveu com outro tipo de agrupamento criando uma rede de reciprocidades com alguns jovens militantes da cultura brasileira e cientistas sociais e que lhe acompanharam por toda a sua trajetória. Nos contatos com o Partido Comunista Brasileiro-PCB e a Escola de Sociologia, conheceu a intelectualidade modernista a partir de Oswald e Mario de Andrade, Lévi-Strauss, Oscar Niemeyer, Monteiro Lobato, Florestan Fernandes e Fernando Henrique Cardoso (ZARVOS, 2007: 234).

Das experiências de vida de Celso Furtado e Darcy Ribeiro que coincidem, estão a ação simultânea da reflexão teórica e literária sobre os temas relativos ao Brasil e a América Latina e as experiências no exercício do poder do Estado e de instituições que agregavam uma intelectualidade comprometida com a utopia das liberdades sociais e democráticas, do planejamento, da economia e da política.

Neste roteiro, Celso Furtado pertenceu aos quadros de formação da Comissão Econômica para a América Latina-CEPAL, debateu a criação da SUDENE no governo Juscelino Kubitschek, foi o primeiro superintendente deste órgão destinado a planejar o 
desenvolvimento econômico e social do Nordeste (1959), ministro do planejamento no governo João Goulart (1962) quando coordenou o Plano Trienal e o Plano Trienal de Educação (1962). Após o longo exílio, exerceu o cargo de ministro da cultura no governo de José Sarney (1986-1988).

De sua convivência com as comunidades indígenas, Darcy Ribeiro foi o fundador do Museu do Índio, acompanhou Anísio Teixeira no Centro Brasileiro de pesquisas Educacionais-CBPE (1957), debateu o início do projeto da Universidade de Brasília no governo JK (1959), ministro da Educação do período parlamentarista no Brasil (1962), ministro da Casa Civil (1963). Após o exílio e com a redemocratização do país, foi eleito vice-governador do estado do Rio de Janeiro (1982) tendo atuação destacada na criação do Programa Especial de Educação Pública, núcleo fundador dos Centros Integrado de Educação Pública, os CIEPs, nos anos 1980.

\section{A convergência a partir do Nacionalismo-desenvolvimentista}

Os anos 1950-1960 são o período onde mudanças demográficas, um fluxo populacional dinâmico e em movimento fez com que o Brasil tivesse uma expansão populacional nas capitais e nos centros urbanos. Um tempo histórico distinto não só pelo ato de descontinuidade do regime democrático liberal, mas também pelo cenário de diversa riqueza cultural, numa ação de intelectuais, artistas e escritores que formularam um acervo de produções nas ciências sociais, na literatura e nas artes, promoveram olhares plurais sobre o país e, na perspectiva de um despertamento, propuseram em seus debates e reflexões um projeto nacional de desenvolvimento. As consequências da industrialização alavancada a partir de 1930 remodelou o país de forma importante na área das sociabilidades.

Na economia, na sociologia-antropologia e na educação, personagens do status de Celso Furtado e Darcy Ribeiro, Paulo Freire e Anísio Teixeira, como operadores de governo e de Estado ou como intérpretes da formação da sociedade brasileira, idealizaram um processo civilizatório autônomo latino-americano e brasileiro. A utopia do desenvolvimento econômico e social esteve presente através dos projetos políticos que transitaram nos lugares comuns onde Darcy Ribeiro e Celso Furtado frequentaram e 
conceberam o desenvolvimentismo com um projeto de poder de caráter nacional de mudanças sociais.

Ressaltamos que Darcy Ribeiro e Celso Furtado tiveram trajetórias singulares, bem como suas formações enquanto intelectuais foram pautadas por experiências próprias e pessoais. Mas cabe refletirmos sobre as marés da conjuntura histórica, no recorte de um tempo que determinará a aproximação de um amplo espectro de correntes políticas e filosóficas, de lideranças partidárias e da sociedade, de instituições e de seus intelectuais orgânicos e pensadores sobre o Brasil na confluência de um ideário defensor das riquezas naturais do país a serem exploradas à favor das massas sociais, de uma concepção de Estado como protagonista do desenvolvimento nacional onde o planejamento seria instrumento da racionalidade de intervenção e controle do capitalismo, nos investimentos em infraestrutura necessários à promoção da justiça social.

A compreensão de Furtado sobre as teses do desenvolvimento latino-americano com a ênfase da perspectiva nacionalista, demonstrava seu o comprometimento político do o país: "É por essa razão que a mística do desenvolvimento tem entre nós uma dimensão nitidamente nacionalista. Não reconhecer um sentido positivo nesse nacionalismo e emprestar-lhe necessariamente diversos é incapacitar-se para a identificação de elementos irredutíveis de nossa realidade social presente" (FURTADO, 2014: 349). ${ }^{3}$

Em sua formação política, Darcy Ribeiro propôs uma junção de expectativas diante do quadro de disputas de poder pelos grupos antagônicos representados no Brasil, entre as correntes conservadoras e liberais com o campo à esquerda. Situa-se desta forma buscando uma síntese entre o socialismo e a experiência do trabalhismo brasileiro, incorporando os movimentos sociais rurais, mais precisamente, na linguagem da época, o campesinato, nas lutas pela reforma agrária, e o operariado, na reforma urbana, pelo controle das multinacionais e, enfim, o destino para uma profunda revolução social. Em seu relato, Ribeiro incorpora sua utopia republicana a partir dos marcos históricos da Revolução de 1930 e o emblema do suicídio de Getúlio Vargas, em 1954 e expõe, de forma singular evidências de um nacionalismodesenvolvimentista:

\footnotetext{
${ }^{3}$ Esta declaração de Celso Furtado faz parte de seu discurso na IV Sessão Plenária da OEA, ocorrida em outubro de 1962, realizada na Cidade do México, quando chefiou a delegação brasileira. A pauta principal do encontro seria a análise do programa da Aliança Para o Progresso, proposto pelos EUA como ação política e econômica para toda a América Latina.
} 
Tratava-se de levar à frente a Revolução de 1930, criando um governo nacionalista, capaz de enfrentar o estrangulamento imperialista. Um governo vinculado aos sindicatos, capaz de mobilizá-los para grandes atos de massa. Um governo socialmente responsável ante as populações pobres da cidade e do campo. Um governo orientado para o capitalismo de Estado, capaz de fortalecer as grandes empresas públicas como a Petrobrás, a Vale, a CSN, o Banco do Brasil e de criar novas empresas públicas, como a Eletrobrás e a Embratel. Um governo predisposto a realizar a reforma urbana, que garantisse aos trabalhadores pobres a propriedade de sua moradia, chamando ao poder público as relações com os proprietários da terra que ocupavam (RIBEIRO, 1997: 292/293).

Das instituições de onde emanaram as bases do nacionalismodesenvolvimentista brasileiro, está a Comissão Econômica para a América Latina CEPAL, e suas teses sobre o desenvolvimento econômico do capitalismo periférico a partir dos estudos sobre as teses sobre a substituição de importações, a industrialização, a tecnologia e a educação como elementos essenciais para o desenvolvimento latinoamericano, serviram como ideário e formulação.

O Instituto Superior de Estudos Brasileiros - ISEB, pautando uma agenda de debates sobre o nacionalismo e o desenvolvimento como ideologia e a crítica ao subdesenvolvimento, apontava um conjunto de ideias e expectativas para o avanço econômico e social do país. Em seu curto período de existência, de 1955 e extinto pela ditadura civil-militar, em 1964, foi um dos principais centros de debates e reflexões sobre o Brasil, agregando ali um eclético grupo de intelectuais, dentre eles, Roland Corbisier, Guerreiro Ramos, Álvaro Vieira Pinto, Hélio Jaguaribe e Cândido Mendes. ${ }^{4}$

$\mathrm{Na}$ efervescência da década de 1960, a cultura libertária da juventude que reverberou a partir dos movimentos de defesa dos direitos civis e das reformas universitárias nos EUA e na Europa, o desenvolvimentismo espraia-se como bandeira de vanguarda nas camadas médias e populares da sociedade brasileira. FARIA (1997: 20), traduziu o ambiente deste período da seguinte forma, quando afirma que, "algumas ideias que nortearam o comportamento político-social da juventude universitária dos anos 60 são as do nacional-desenvolvimentismo, de paz e amor, de uma juventude

\footnotetext{
${ }^{4}$ Darcy Ribeiro e Celso Furtado não foram diretamente orgânicos no ISEB, mas contribuíram nas reflexões e em alguns momentos, atuando em seus conselhos consultivos, junto a Anísio Teixeira.
} 
revolucionária e quase profética, da dicotomia esquerda-direita, da contracultura, da igualdade de direitos para negros e mulheres e da liberdade sexual".

Nas disputas eleitorais, o contraponto ideológico da União Democrática Nacional-UDN, sob a liderança do governador do Estado da Guanabara Carlos Lacerda, representava os interesses do capital internacional e do empresariado brasileiro, agregando setores consideráveis da classe média brasileira, seduzida pelo discurso pautado por um moralismo de comportamento em defesa dos valores tradicionais da família católica-cristã e um forte apelo contra a corrupção, desprezando a ordem institucional e as regras da frágil democracia liberal deste período, apostando sempre na crise e nas tentativas de golpe de Estado. Criado em 1945 por Getúlio Vargas, o Partido Trabalhista Brasileiro-PTB, agregou o trabalhador urbano na proteção aos seus direitos, onde o viés de um nacionalismo que defendia as riquezas naturais para o bem próprio e usufruto da sociedade brasileira. O PTB seria a expressão principal do projeto político do nacionalismo-desenvolvimentista, resguardando aqui setores importantes do Partido Comunista Brasileiro-PCB. ${ }^{5}$

O ideário do nacionalismo-desenvolvimentista teve sinais evidentes de presença no Plano de Metas de JK, bem como em seu governo dos 50 anos em 5, sendo o ícone deste tempo a construção de Brasília: o despertamento nacional para o futuro e da prosperidade social. Perpassou também o breve e confuso governo de Jânio Quadros e deu sentido programático no período das crises institucionais ao governo João Goulart. No planejamento educacional, esta perspectiva motivou um esforço em organizar a educação nacional, esta vista como elemento propulsor do desenvolvimento econômico e social. A palavra planejamento simbolizou este tempo e esteve intrinsecamente vinculado às reflexões e ações de Darcy Ribeiro e Celso Furtado.

\section{Darcy Ribeiro e Celso Furtado: Planejamento e Educação como projeto de revolução social}

\footnotetext{
${ }^{5}$ Esse movimento de reformas, termo utilizado por Ribeiro (1997:293), aglutinava um grupo vinculado ao PTB, uma geração de juristas, políticos, sindicalistas que convergiam nas ideias das utopias do nacionalismo-desenvolvimentista: Almino Affonso, Sérgio Magalhães, Temperani Pereira, Bocayuva Cunha, Rubens Paiva, Doutel de Andrade, Benedito Cerqueira, José Gomes Talarico, dentre as lideranças de João Goulart e de Leonel Brizola. As bases teóricas do Trabalhismo vêm das reflexões do professor Alberto Pasqualini, principal ideólogo desta vertente de pensamento doutrinário, muito presente nos anos 1950-1960 no Brasil.
} 
As influências do Keynesianismo, principalmente a partir das vivências históricas do New Deal, no governo norte-americano do presidente Roosevelt (19331937) e os investimentos do Plano Marshal (1948) para a reconstrução da Europa pós Segunda-Guerra, a ideia de planejamento toma força considerando estas conjunturas, a tendência de que caberia ao Estado atuar no controle e a expansão do desenvolvimento, outra expressão chave que assumiu importância entre os anos de 1950 e 1960. (HOBSBAWM, 1995: 105-112, 283-295).

Algumas expressões tiveram significado ideológico deste campo político de atuação no país: esperança, reformismo, distributivismo, modernização e nacionalismo foram elementos integradores de um projeto desenvolvimentista, que, nas afirmativas de Lucília de Almeida Neves (2010), determinado entre 1940 até a década de 1960. (SANTOS, 2019: 3).

A partir de JK, o termo planejamento e o seu sentido passaram por uma naturalização no vocabulário dos governos e da política, com forte influência cepalina e o princípio de se pensar o desenvolvimento do país a longo prazo: Plano de Metas (1956-1960), plano econômico de austeridade (1961), plano trienal (1963-1965 interrompido com o golpe civil-militar), plano trienal da educação (1963); plano nacional de educação (1963-1970, também suspenso com o golpe civil-militar em 1964).

É importante percebermos o protagonismo político de Darcy Ribeiro e de Celso Furtado, o trânsito destas duas figuras no período dos anos 1960, ambos na faixa dos 40 anos, jovens atores num contexto de profunda crise, exercendo papeis estratégicos na experiência de conduzirem o país nas expectativas de um projeto de inclusão das massas sociais à renda e salários justos, terra, emprego, educação e saúde.

Nos anos de 1962 e 1963, Furtado foi Ministro do Planejamento, o primeiro ministro do planejamento do Brasil, sendo a liderança que coordenou a elaboração e a condução do Plano Trienal, a pedido de João Goulart, que tinha o interesse de apresentar ao país os eixos possíveis para as reformas de base, além das alternativas para o controle inflacionário da época. Sua trajetória inicial na Superintendência de Desenvolvimento do Nordeste (SUDENE) e a imagem conquistada ao longo do tempo e na passagem que teve no governo JK, garantiu-lhe um perfil respeitado de planejador, mesmo com a forte oposição udenista que lhe taxava de ser homem perigoso e "comunista", isto por defender a reforma agrária e olhar o nordeste brasileiro como 
elemento de superação regional da miséria para o salto qualitativo ao desenvolvimento econômico do país.

Darcy Ribeiro exerceu a função de ministro da educação entre os meses setembro de 1962 até janeiro de 1963, no período do parlamentarismo, no Gabinete do primeiro-ministro Hermes Lima. Propôs ao Conselho de Ministros o Programa de Emergência do Ministério da Educação e Cultura e defendeu junto ao Conselho Federal de Educação o primeiro Plano Nacional de Educação da república, onde o relator do processo foi Anísio Teixeira. Em 1963, foi convidado a assumir a Casa Civil da Presidência da República, no auxílio mais direto a João Goulart, que recuperara, através de plebiscito, a presidência da república, acumulando assim as chefias de Estado e de Governo. A convergência da utopia do nacionalismo-desenvolvimentista, no zelo de elaborar os planos educacionais aproximou Furtado às ideias de Darcy e Anísio Teixeira, num ambiente de reformas educacionais e nos embates que foram travados na aprovação da lei no 4.024/61, a primeira Lei de Diretrizes e Bases da Educação Nacional (SANTOS, 2019: 6).

Mesmo considerando que a trajetória acadêmica de Celso Furtado foi pautada nos estudos da história econômica do Brasil, este intelectual paraibano percebia a importância da educação no contexto do desenvolvimento econômico-social. Desta forma, o investimento no fator humano via educação, termo utilizado constantemente por Furtado em seus artigos e apontamentos sobre a realidade brasileira, ao longo prazo, consolidaria as condições necessárias para se derrotar o subdesenvolvimento. $\mathrm{O}$ fator humano na perspectiva furtadiana não se limitava ao simples aprimoramento de mão de obra operária ao projeto de industrialização país, mas principalmente como a inclusão das massas sociais, às riquezas produzidas em território nacional, acesso às políticas sociais articuladas ao desenvolvimento. Furtado debateu a ação estratégica da Educação como elemento essencial para o desenvolvimento, mas também como um possível processo histórico e civilizatório brasileiro.

Um amplo programa social deve dar prioridade à habitação e à educação antes do investimento reprodutivo. A educação interfere no tempo, e, melhorando-se a qualidade do fator humano, modifica-se por completo o quadro do país, abrem-se possibilidades de desenvolvimento muito maiores. Não há país que tenha conseguido se desenvolver sem investir consideravelmente na formação de gente. Em criança eu já ouvia falar no Japão; já que tinha alfabetizado $100 \%$ da população no fim do século 
XIX. Esse é o mais importante investimento a fazer, para que haja não só crescimento, mas autêntico desenvolvimento (FURTADO, 2002: 11). ${ }^{6}$

Nesta teia de relacionamentos e de reciprocidades no campo da política, Darcy Ribeiro e Celso Furtado como intelectuais e operadores do Estado somaram esforços em reconhecer a educação como elemento fundamental para um projeto autônomo de país. Junto ao Plano Trienal e do Plano Nacional de Educação, o Plano Trienal da Educação $(P T E)$, foi a expressão objetiva do governo João Goulart dando sentido às políticas sociais na educação, consagradas nas bandeiras das reformas de base. Entre o Plano Trienal e o Plano Nacional de Educação, o Plano Trienal da Educação se fazia presente como o compromisso do governo Jango em detalhar, para os três anos de seu mandato, as reformas de base para a educação. Percebe-se então que o PTE (1962) buscava conciliar os princípios da lei no 4.024/61 e o Plano Nacional de Educação, mas limitado ao tempo de governo de Jango. Cabe então percebermos que o Plano Trienal de Educação, única extensão de política pública específica do Plano Trienal, é concebido como planejamento de governo, e o plano nacional de educação, um planejamento para os dez anos seguintes, por isso um planejamento de Estado.

\section{O desterro, o incômodo e o regresso: $A$ utopia republicana em jogo}

O golpe civil-militar de 1964 não só interrompeu um projeto de desenvolvimento em curso no Brasil, mas também espalhou brasileiros pelo mundo, agrupando-os em outros lugares, proporcionando uma rede de reciprocidades entre aqueles que se constituíram opositores ao autoritarismo brasileiro. No ambiente desta primeira diáspora brasileira, expressão utilizada por Furtado para as consequências do golpe, citou a sua aproximação com Darcy Ribeiro e os seus movimentos e de outros

\footnotetext{
${ }^{6}$ A perspectiva educacional e cultural no pensamento de Furtado é corroborada em outra obra Um Projeto Para o Brasil: "Em diversas oportunidades, fizemos referências ao fato de que o desenvolvimento econômico, na forma em que ele se processa hoje em dia, é essencialmente uma questão de criação e assimilação de progresso tecnológico. Essa afirmação deveria ser completada por outra: o progresso tecnológico é principalmente uma questão de qualidade do fator humano. Estamos aqui em face do mais complexo de todos os problemas que coloca uma política de desenvolvimento: melhorar o fator humano toma tempo e somente é possível se se dispõe de matrizes adequadas ... o nível de desenvolvimento de um país é função da massa de investimentos incorporados no fator humano. Desta forma, o problema do progresso tecnológico e o da melhoria do fator humano, estará sempre intimamente relacionados" (FURTADO, 1969: 83).
} 
exilados que buscavam definir as suas vidas no exterior, apesar das dúvidas quanto à duração do regime estabelecido no país. ${ }^{7}$

Darcy viajou pela América do Sul estando primeiramente no Chile, depois, se estabeleceu no Uruguai, foi professor de antropologia na Universidade de Montevidéu auxiliando o governo na reforma universitária daquele país, permanecendo ali por quatro anos. Furtado chegou ao Chile em maio de 1964, um mês após golpe civil-militar ocorrido no Brasil e antes de buscar o seu exílio definitivo na França, esteve nos EUA. No Chile, o primeiro ponto de chegada dos que saíram do Brasil, um grupo restrito de intelectuais brasileiros encontravam-se para debater o futuro e a resistência ao poder civil-militar no país. Dentre eles estavam Paulo Freire, Francisco Oliveira, Estevam Strauss, Fernando Henrique Cardoso, Jader de Andrade, Cid Carvalho, os próprios Darcy Ribeiro e Celso Furtado, Thiago de Melo, Samuel Wainer (SANTOS, 2014: 166).

A complexa conjuntura dos anos 1950-1970 na América Latina demonstrava a sucessão de golpes militares na região: Venezuela (1962), Brasil (1964); Bolívia (1964, 68 e 73); Argentina (1966 e 1974); Uruguai (1973); Chile (1973), Equador (1973), fez com que Darcy Ribeiro e Celso Furtado caminhassem pelo mundo. A personalidade irrequieta de Darcy Ribeiro fez com este mineiro de Montes Claros saltasse de país em país pela América do Sul, assessorando governos em reformas educacionais e universitárias. Darcy voltou ao Brasil em 1968, sob a proteção de um habeas-corpus, porém, pego pelo Ato Institucional no. 5, foi preso acusado de liderar o movimento subversivo no Uruguai, retornando, em 1969 ao exílio, rumando para a Venezuela. Em 1971, assessorou o presidente chileno Salvador Allende, e em 1972 acompanhou no Peru a ascensão de Velasco Alvarado e o assessorou na reforma educacional. ${ }^{8}$

No registro de suas memórias, Darcy Ribeiro dividiu o seu exílio em três partes: Uruguai e a prisão (1964-1968); o segundo exílio: Caracas, Chile, Peru e na constatação de uma enfermidade e, por fim, o terceiro exílio, saindo do Peru em plena crise política e institucional e retornando, mais uma vez, para o Brasil. Seu relato sobre as idas e

\footnotetext{
${ }^{7}$ No artigo, As cartas do desterro: conversas entre Darcy Ribeiro e Celso Furtado sobre a América Latina, universidade e o projeto brasileiro interrompido (1969-1970), há uma análise das correspondências trocadas entre Darcy Ribeiro e Celso Furtado no período do exílio contendo as impressões de cada um sobre o golpe no Brasil e as suas expectativas diante deste período da política brasileira (SANTOS, 2014). ${ }^{8}$ recondo (2018: 217-218) traz o relato das disputas internas do Supremo Tribunal Federal quanto ao julgamento do habeas corpus de Darcy Ribeiro, as teses favoráveis e as contrárias: “... o ministro argumentou de que os militares prendiam primeiro para apurar depois, prática abolida desde a década de 1930: A ilegalidade e o arbítrio da ameaça que pesa contra o paciente parecem-me sobejamente comprovados - ponderou".
} 
vindas e o incômodo do regime civil-militar sobre a sua presença no país refletia a angústia daqueles que não poderiam mais, naquela conjuntura, buscar uma vida comum em seu próprio país, por causa de sua "periculosidade":

Expulso do Brasil pela ditadura militar, mal podia ficar no pouso único que tinha no mundo, que era peruano. A pressão militar para a minha saída do Brasil acabou ficando irresistível após seis meses de convalescença. Argumentavam que, para manter minha segurança com os quatro policiais que me guardavam, gastavam o preço da segurança de um embaixador estrangeiro. Isso não podia mais ser admitido. Acabaram convencendo meu advogado, que me aconselhou a sair. Dizendo que o temor da segurança do governo era que eu fosse vítima dos terroristas do próprio governo, que não admitiam minha presença no Brasil. Que fazer? Saí novamente para o desterro (RIBEIRO, 1997: 446).

Diferentemente de seu colega de governo no período Jango, Celso Furtado partiu primeiramente para o Chile e depois para os Estados Unidos (1964), fixando-se na Universidade de Yale, situando-se em New Harven, entre Nova York e Boston, onde buscou recuperar sua trajetória acadêmica numa instituição que se dedicava a estudar o desenvolvimento do Terceiro Mundo: "Tinha consciência de que me afastava do Brasil e da América Latina por muito tempo, e não me escapava que os obstáculos e enfrentar não seriam pequenos" (FURTADO, 2014: 435).

A permanência em território norte-americano lhe trouxe o prazer em visitar e buscar contatos no meio acadêmico e científico, participando de seminários e conferências nas Universidades daquele país, Europa e América Latina, mas o ambiente interno anticomunista e macartista, acirrado pela Guerra-Fria, fez com que Furtado refizesse seu planejamento no exílio. O regime autoritário brasileiro buscou acompanhar a vida de Celso Furtado nos EUA, trazendo-lhe constrangimento, principalmente quanto ao controle de seu passaporte e as tentativas do economista em visitar países do continente latino-americano e a Europa.

Em junho de 1965, ao receber o convite da Universidade de Paris-Sorbone, fixou-se na França. Em sua autobiografia, registrou a satisfação da convivência com alunos e pesquisadores, o esforço em conceber naquela universidade, um centro de estudos sobre o desenvolvimento econômico e social latino-americano. No exílio e em sua longa jornada na França, na distância de sua terra e cultura, exercitou o magistério, escreveu artigos para os jornais, inclusive o Le Monde, orientou um imenso somatório de teses sobre o desenvolvimento e o subdesenvolvimento no Terceiro Mundo, criou 
uma geração de intelectuais, seus alunos, muitos oriundos dos países que se tornaram objeto de suas investigações: "Alguns alunos meus dessa época vieram a ocupar cátedras nas universidades em seus países, outros se destacaram em cargos de governo, como ministros de Estado..." (FURTADO, 2014: 491).

A longa duração do regime autoritário no Brasil e o exílio, fez com que Celso Furtado e Darcy Ribeiro consolidassem uma trajetória de êxito como cientistas e pensadores sobre a América Latina e seus povos, sobre os problemas brasileiros e as suas alternativas de superação enquanto projeto de país. O respeito adquirido pelo mundo não só fortaleceu a imagem destes dois personagens da república brasileira, mas auxiliou-os na pressão internacional, dos órgãos defensores dos direitos humanos e das liberdades civis, junto ao governo civil-militar.

Em 1970, em Barbados, através do Conselho Mundial de Igrejas-CMI, Darcy Ribeiro participou da reunião que redefiniu a linha de atuação missionária da Igreja Católica, produzindo um documento que estabeleceu uma dura crítica à história da catequese indígena. (ZARVOS, 2007: 235). Neste mesmo período (1972-73), Furtado transitou entre ser professor visitante na American University, em Washington e professor da Universidade de Cambridge, na Inglaterra (D’AGUIAR FREIRE, 2013: 256).

O protagonismo do CMI, em oposição aos governos autoritários espalhados pelo mundo, apresentou em março 1971, um dossiê sobre a tortura no Brasil, e ao mesmo tempo a Anistia Internacional, em 1972 apresentou o seu primeiro relatório sobre a tortura e a ênfase deste documento esteve nos relatos daqueles que foram presos e torturados no Brasil.

Os sinais efetivos da transição do agonizante regime civil-militar à retomada da democracia liberal no país tiveram como primeiro ato de enfrentamento o protesto contra a morte do jornalista Vladimir Herzog, em 1975. Sob a liderança do Cardeal D. Paulo Evaristo Arns, da Arquidiocese de São Paulo, o culto ecumênico de corpo presente do jornalista contou com aproximadamente dez mil pessoas e se transformou num encontro de protesto contra a ditadura militar. Com a criação dos Comitês Brasileiros pela Anistia-CBAs, a partir de 1978, espalhou-se pelo país um movimento organizado e que seria um porta-voz do desejo de retorno daqueles que saíram do país com o golpe de 1964 (ARAÚJO, 2007: 332-338).

A crise do Petróleo (1973-74) coincidiu com o fim do Milagre Econômico, processo que no Brasil trouxe uma falsa sensação de um ambiente de prosperidade 
econômica e se traduziu, na realidade, como uma profunda concentração de riquezas, desemprego e ritmo acelerado da inflação. A Lei da Anistia, de 1979, significou um avanço das forças democráticas e de oposição à ditadura civil-militar desencadeando no país um amplo movimento em defesa da retomada às normalidades constitucionais no contexto do resgate do poder civil, numa nova agenda econômica e social, da liberdade de expressão e dos direitos sociais.

A conjuntura da década de 1970 expôs a luta pelas liberdades civis e democráticas, a reconfiguração das representações sociais, no novo sindicalismo que se apresentava no $\mathrm{ABC}$ paulista, nas comunidades eclesiais de base e nas lideranças de oposição, aglutinada neste primeiro momento no Movimento Democrático BrasileiroMDB. As eleições de 1974 indicavam o desgaste do regime, com a vitória das oposições e a ascensão de figuras da transição e das resistências: Marcos Freyre, Fernando Lyra, Jarbas Vasconcelos, Lysâneas Maciel, do campo progressista, além das referências na defesa do retorno do país ao estado de Direito; Tancredo Neves, Franco Montoro, Mário Covas e Ulysses Guimarães (ARAÚJO, 2007: 335).

Mesmo com a moradia fixa na Europa e buscando reconstruir sua carreira acadêmica no período do exílio, o economista paraibano esteve no Brasil algumas vezes, durante a vigência do regime. Em 1968, Furtado foi convidado pela Comissão de Economia da Câmara dos Deputados para proferir duas palestras sobre a economia brasileira. Dos dois encontros realizados, surgiu o primeiro ensaio e que consta de sua obra, Um Projeto para o Brasil (1969). Esteve ainda em território nacional em 1975, onde ministrou por um semestre, o seminário sobre a economia em desenvolvimento, na PUC-SP.

É preciso percebermos que figuras tais como Darcy Ribeiro e Celso Furtado, bem como aqueles que lutaram contra o arbítrio no país, foram vitoriosos diante do que foi imposto entre os anos de 1964-1985. Ambos, ao retornarem ao Brasil, reestabeleceram suas trajetórias, conciliando os papeis de intelectuais e operadores do Estado.

Já em plena liberdade para regressar e transitar pelo Brasil, em 1985 Celso Furtado foi convidado por Tancredo Neves a integrar a Comissão do Plano de Ação do Governo e mais uma vez surgiu a possibilidade de contribuir com o país na transição dos regimes. Em agosto deste mesmo ano, foi nomeado embaixador para a Comunidade Europeia e ainda auxiliou a comissão de estudos constitucionais para fins de discussão de uma nova constituição, pós regime civil-militar. Sua atuação como ministro da 
Cultura do governo José Sarney (1986-1988), teve o mérito de compreender esta pasta enquanto política pública de Estado, onde elaborou e implementou a primeira lei de incentivos fiscais. (D’AGUIAR FREIRE, 2013).

A Lei de Anistia impulsionou Darcy Ribeiro na recuperação das suas atividades políticas e civis, apesar de ter retornado ao Brasil em 1976. A partir de 1979, tornou-se professor titular da Faculdade de Filosofia e Ciências Sociais, da Universidade Federal do Rio de Janeiro-UFRJ. Ao mesmo tempo, aproximou-se de Leonel Brizola, construindo o projeto educacional que se tornou um dos emblemas nacionais de recuperação da ideia da universalização da escola pública integral para todos, apesar do duro combate dos setores conservadores, principalmente presentes na mídia. Junto a Brizola, venceu as eleições para o governo do Estado do Rio de Janeiro (1982) e, como vice-governador, acumulou as funções de secretário de estado de Ciência e Cultura, diretor do Teatro Municipal, da FUNARJ, e coordenador do Programa Especial de Educação-PEE, sendo o condutor para a construção dos CIEPs (ZARVOS, 2007: 236).

Para discutirmos a atuação de Darcy Ribeiro e o seu envolvimento com o projeto educacional no estado do Rio de Janeiro, propomos aqui uma leitura de outros dois personagens, tão importantes quanto a Darcy, na perspectiva de se olhar os CIEPs e sua importância social e política, Leonel Brizola e Oscar Niemeyer. ${ }^{9}$

Para Leonel Brizola, a ideia republicana de que a educação pública universalizada seria um dos marcos de garantia para que as camadas populares ao acesso a uma escola de qualidade, vinha de sua própria experiência de vida, como aluno oriundo da escola pública no Rio Grande do Sul, formando-se no Instituto Agrícola de Viamão, como técnico rural, em 1939. Em 1945 ingressou na Escola de Engenharia da Universidade do Rio Grande do Sul, concluindo-o em 1949. Eleito prefeito de Porto Alegre (1955) e governador do estado do Rio Grande do Sul (1958), promoveu um conjunto de políticas públicas para a educação, ampliando o acesso de crianças e adolescentes às redes públicas de ensino e valorizando o magistério, além da atuação na nacionalização de empresas multinacionais e de um arrojado investimento nas políticas agrícolas do estado. Estas medidas repercutiram de tal forma que seu nome se tornou nacionalmente conhecido.

\footnotetext{
${ }^{9}$ Os três paradigmas de fundação dos CIEPs: O projeto político castilhista de Leonel Brizola, o traço modernista e o ideal libertário-comunista de Oscar Niemeyer e a utopia cabocla de Darcy Ribeiro. In. SANTOS, L. A. (2011). Entre a utopia e o labirinto: democracia e autoritarismo no pensamento educacional brasileiro dos anos 1980. Rio de Janeiro, RJ: Quartet/Faperj.
} 
A cultura gaúcha, castilhista-positivista, provocou-lhe a compreensão de que o primado da ciência e da razão seriam os fundamentos de uma república cidadã, de oportunidades para todos. Desta forma, a linhagem do pensamento de Brizola em relação a educação, vem de seu universo cultural, político e da sociabilidade gaúcha. Cabe aqui questionarmos a ideia simplista de que, para Brizola, os CIEPs foram mera propaganda eleitoral para sua ascensão à presidência da república. ${ }^{10}$

Na projeção estética do que viriam a ser os CIEPs, Oscar Niemeyer não fugiu de seus princípios que basearam suas ideias de espaço, lugar, de pertencimento, enfim, uma geografia a ser percorrida e que exprimisse a livre circulação das diversidades culturais, de crianças, professores e comunidades, dos conhecimentos e de pessoas (sinais de uma idealização da utopia comunista aos olhos do arquiteto?). A massa concreta com as esquadrias de alumínio lembrava o seu mestre da arquitetura Le Corbisier, inspiração permanente em suas obras e formas, onde os CIEPs se integram numa linha do tempo, no conjunto de obras pensadas e elaboradas pelo arquiteto-artista modernista.

Para Darcy Ribeiro, os CIEPs simbolizavam a garantia de acesso e permanência de uma massa populacional de crianças e adolescentes que, no início da década de 1980 demonstrava o saldo da precarização da educação pública deixada pelos governos militares. O sonho da universalização do ensino no país, foi embalado por Darcy a partir da convivência com Anísio Teixeira na experiência do Centro Educacional Carneiro Ribeiro ou Escola Parque, criado em 1950, na Bahia, sob a inspiração do próprio Anísio, uma escola pública, de tempo integral conciliando a educação humanista com as iniciativas de formação profissional. Em seu projeto pedagógico, buscava-se a síntese de um pensamento eclético que iria do escolanovismo brasileiro, entremeando-se às

\footnotetext{
${ }^{10} \mathrm{O}$ termo populismo pode ser observado a partir de duas vias. Na primeira, há uma cultura do senso comum, muito presente nas classes medias brasileiras, que propõe uma generalização aplicando um sentido pejorativo onde políticos e governantes demagogos são aqueles que acenam com um discurso preferencial aos mais pobres, mas que são efetivamente todos corruptos. No campo das ciências sociais no Brasil, os tradicionais estudos de Francisco Weffort e Octavio Ianni sobre a interpretação do populismo como um vetor de uma parte das elites brasileiras, bem próximas das camadas populares, mas que representam efetivamente os interesses da classe dominante. Desta forma, as medidas ou políticas públicas voltadas para o atendimento das massas sociais desprovidas de seus direitos, seriam percebidas como controle social das elites. Analisam então o fenômeno político daquelas lideranças, sejam articuladas no nacionalismo-desenvolvimentista, ou como lideranças, tais como Getúlio Vargas, João Goulart (Darcy Ribeiro e Celso Furtado), Anísio Teixeira e Paulo Freire, Leonel Brizola, Lula, dentre outros. Há, de certa forma, uma convergência entre essas duas vias. Nesta perspectiva, os autores deste artigo, propõem uma revisão deste temo populismo, realizando uma releitura crítica, considerando as referências: FERREIRA, Jorge (Org.) (2010). O Populismo e sua história: Debate e Crítica. RJ. Editora Civilização Brasileira, em especial o artigo de GOMES, Ângela de Castro. $\boldsymbol{O}$ Populismo e as Ciências Sociais no Brasil: Notas sobre a Trajetória de um Conceito. (p. 17-57). Recomendamos ainda, como contraponto, WEFFORT, Francisco (2003). O Populismo na política Brasileira. SP. Paz e Terra Editora.
} 
ideias de John Dewey, Paulo Freire e Carl Rogers, e no ideário construtivista de Emília Ferreiro.

Os CIEPs foram uma invenção determinada pela conjuntura brasileira dos anos 1980, das ideias oriundas do socialismo democrático europeu, apreendido por Brizola em seus anos de exílio, no contato com as lideranças da Internacional Socialista, dentre elas o alemão Willy Brandt, o francês François Miterrand e os ibéricos Mario Soares e Felipe Gonzales. Sob as consequências da perversa política do regime civil-militar que resultou no enfraquecimento da escola pública no país e uma ampla população infantil excluída da escola, da pobreza e miséria espalhadas em território nacional, os CIEPs projetavam atender a esses, democratizando o acesso, garantindo-lhes sinais de um possível Estado de Bem-estar Social.

Os CIEPs seriam também a expressão de uma democracia da diversidade, onde a história e a cultura africana seriam estimuladas, num espaço onde o conhecimento articulava-se com o esporte e a agitação cultural a partir do envolvimento dos artistas locais dos municípios espalhados pelos municípios fluminenses, onde as linguagens das artes plásticas, cênicas e musicais, buscavam inserir no currículo escolar da educação básica um resgate da escola aos padrões defendidos pela Escola Nova. Os serviços sociais, oferecidos com a atuação de dentistas e médicos, somados a uma política de educação alimentar, faziam dos CIEPs uma referência local de desenvolvimento e organização das comunidades. Na idealização de Darcy Ribeiro, os CIEPs anteciparam, em seu projeto político-pedagógico em seu primeiro Programa Especial de Educação (1982-1986), o que seria consagrado na constituição de 1988 e na Lei de Diretrizes e Bases da Educação Nacional de 1996: alimentação escolar obrigatória, currículo escolar e as ênfases à educação indígena e africana, políticas para a educação de jovens e adultos, gestão democrática, política de distribuição do livro didático e de literatura infantil, etc.

Em 1991, Darcy elegeu-se Senador da República e participou da redação da Lei de Diretrizes e Bases da Educação Nacional, pelo estado do Rio de Janeiro, sendo o relator da Lei 9394/1996. 


\section{Sobre o ofício de se pensar e agir...}

Darcy Ribeiro e Celso Furtado foram personagens de seu tempo. Um tempo de longa duração, na fértil convivência entre o exercício de se pensar e experimentar o mundo. A dupla função de intelectuais e operadores do Estado fez com que um paraibano e um mineiro dessem um sentido para as suas vidas no comprometimento de um país justo, perseguindo, cada um ao seu modo, a utopia possível. SAID (2005), nos apresenta duas qualidades nos traços de existência do intelectual. A primeira é na figura representativa desse sujeito e o seu lugar no mundo, aquele que expõe um ponto de vista e articula uma leitura do seu entorno, buscando ser reconhecido por isso. Em outra concepção, o intelectual é percebido como figura pública, não é um profissional sem rosto, pois é partícipe numa vocação que é social, dar sentido e propor uma mensagem, uma atitude, uma filosofia (2005: 25, 27 e 30).

A consciência da sua função no mundo, sua inserção a partir de sua obra e carreira acadêmica articulada ao fazer, tornou Celso Furtado e sua condição histórica um intelectual complexo e de fôlego, traduzindo-se numa dialética da existência, reconhecida por ele próprio:

O intelectual tem de próprio a capacidade sem limites de inventar-se razões para viver. Se está em um país novo para ele, tudo lhe interessa, pois tudo encerra o segredo de outra experiência de vida de homens e mulheres que não compartilham de sua memória e quem viram mil coisas que ele desconhece. A solidão do intelectual é de qualidade diferente. Raramente o domina o sentimento da inutilidade, a angústia do não ser (FURTADO, 2014: 419).

Ao discorrer sobre seu itinerário como intelectual, Darcy relacionou um conjunto de cientistas e professores que lhe ofereceram os caminhos de sua formação, mas sua arguta leitura de toda sua convivência nos meios acadêmicos e ao mesmo tempo na militância comunista, forjou um personagem irrequieto, autocrítico e irônico:

Eu vivia dividido entre o estudante atento e o ativista tarefeiro. Acho muito legítimo estudar qualquer tema só movido pelo desejo de saber, afinal, nosso ofício de cientistas tem por fim ampliar e melhorar o discurso humano sobre a natureza das coisas, inclusive de si próprios. A soma do ativismo político com a herança brasilianista e o interesse pela literatura impediram que eu me convertesse num acadêmico completo, perfeitamente idiota... (RIBEIRO, 1997: 127-143). 
América Latina e Brasil foram a convergência do compromisso ético e histórico de Celso Furtado e Darcy Ribeiro, intelectuais e operadores do Estado. Estes personagens da república brasileira tiveram suas paixões. Darcy não escondia seu orgulho de ter imaginado, concebido e consolidado a Universidade de Brasília-UnB, a partir da convocação de Juscelino Kubitschek, em 1959. A UnB foi a projeção de um país para além do século $\mathrm{XX}$, prospectando na ciência, tecnologia e nas humanidades, um Brasil moderno, democrático e justo, de uma inteligência enlaçada com a prosperidade do país, com os pobres e miseráveis. Para Furtado, a SUDENE, criada em 1959, lhe emocionava porque via em sua fundação a operação possível a vislumbrar o seu Nordeste não como um lugar da fome e do desterro, mas pelo instrumento de libertação, chamado de planejamento, fazer da utopia a revolução de brasileiros, desejando o Nordeste como solução ao desenvolvimento nacional. Pelas obras produzidas e o respeito às carreiras acadêmicas e literárias, ambos ingressaram na Academia Brasileira de Letras-ABL. Darcy Ribeiro, recebido pela ABL em 1993, já Celso Furtado, em 1997.

Embalados num tempo histórico das transformações sociais a partir do póssegunda Guerra Mundial, Darcy e Furtado são de uma geração de brasileiros visceralmente comprometidos com um Brasil para todos e todas, desde as comunidades indígenas, dos negros e negras, trabalhadores urbanos e do campo, no respeito à pluralidade da formação dos povos. Educação e desenvolvimento para esta linhagem de pensadores seriam os marcos da revolução social, desejada objetivamente na curta experiência do governo João Goulart e que se reproduziram na resistência à ditadura, no retorno ao país e na realização projetos seguintes. A UnB, a SUDENE, o Plano Trienal e o Plano Trienal de Educação, os CIEPs, a Cultura percebida como política pública, são os legados desses dois brasileiros, além de um acervo extraordinário na produção literária e acadêmica.

\section{Referências bibliográficas}

ARAÚJO, Maria Paula Nascimento (2007). Lutas democráticas contra a ditadura. In. FERREIRA, Jorge \& REIS, Daniel Aarão. Revolução e Democracia. RJ: Editora Civilização Brasileira.

BIELSCHOWSK, R. (2016). Pensamento econômico brasileiro: o ciclo ideológico do desenvolvimentismo. 5 ed. Rio de Janeiro, RJ: Contraponto. 
D’AGUIAR, Rosa Freire (Org.) (2013). Essencial Celso Furtado. São Paulo: Companhia das Letras.

FARIA, Lia (1991). A utopia possível: revisitando os CIEPs do Rio de Janeiro. Rio de Janeiro: Livros do Tatu. Revista Interinstitucional Artes de Educar (2017). Rio de Janeiro, Número Especial Darcy Ribeiro, v. 3, n. 2: 98-12, jul.-out.

FARIA, Lia (1997). Ideologia e Utopia nos anos 60: Um Olhar Feminino. RJ. EdUERJ.

FUNDAÇÃO DARCY RIBEIRO (1962). Plano Trienal de Educação. 09.00, v. 12: 4344.

FURTADO, Celso (1969). Um Projeto para o Brasil. Rio de Janeiro. Editora Saga. $5^{\text {a }}$ Edição.

FURTADO, Celso (1974). Formação Econômica do Brasil. São Paulo: Companhia Editora Nacional.

FURTADO, Celso (2014). Obra autobiográfica. São Paulo: Companhia das Letras.

GOMES, Ângela de Castro (2001). O Populismo e as Ciências Sociais no Brasil: Notas sobre a Trajetória de um Conceito. In. FERREIRA, Jorge (Org.). O Populismo e Sua História - Debate e Crítica. Rio de Janeiro: Ed. Civilização Brasileira, 2001.

GRAMSCI, Antonio (2006). Cadernos do cárcere. Rio de Janeiro: Civilização Brasileira.

HOBSBAWM, Eric (1995). A Era dos extremos: o breve século XX (1914-1991). São Paulo: Companhia das Letras.

MOTTA, M. (2008). O projeto político: a presidência da república. In: FERREIRA, M. de. M. (org.). A força do povo: Brizola e o Rio de Janeiro. Rio de Janeiro: Alerj: FGV.

RECONDO, Felipe (2018). Tanques e Togas: O STF e a Ditadura Militar. SP. Companhia das Letras.

RIDENTI, Marcelo (2003). Cultura e Política Brasileira: Enterrar os Anos 60?. In. BASTOS, Elide Rugai, RIDENTI, Marcelo, ROLLAND, Denis (Orgs.). Intelectuais: Sociedade e Política. São Paulo: Cortez e Editora: 197-223.

RIBEIRO, Darcy (1984). Nossa escola é uma calamidade. Rio de Janeiro: Salamandra.

RIBEIRO, Darcy (1997). Confissões. São Paulo. Companhia das Letras.

RIBEIRO, Darcy (2006). O povo brasileiro. São Paulo: Companhia das Letras.

SAID, Edward W. (2005). Representações do Intelectual. SP. Companhia das Letras.

SANTOS, Lincoln de Araújo (2011). Reflexões sobre o pensamento social e educacional no Brasil e suas matrizes autoritárias. Revista Eletrônica de Educação. São Carlos, SP: UFSCar, v. 5, n. 2: 9-25, nov. Disponível em http://www.reveduc.ufscar.br).

SANTOS, Lincoln de Araújo (2011). Entre a Utopia e o Labirinto: Democracia e Autoritarismo no Pensamento Educacional Brasileiro dos Anos 1980. Rio de Janeiro. FAPERJ/Quartet.

SANTOS, Lincoln de Araújo (2019). A Alternativa para o Progresso: O Nacionalismodesenvolvimentista, seus intelectuais e o Planejamento Educacional nos anos 1960 no Brasil. Revista Brasileira de História da Educação, v. 19. http://dx.doi.org/10.4025/rbhe.v19.2019.e057.

SANTOS, Lincoln de Araújo (2014). As cartas do desterro: conversas entre Darcy Ribeiro e Celso Furtado sobre a América Latina: Universidade e o projeto brasileiro interrompido (1969-1970). Terceiro Milênio: Revista Crítica de Sociologia e Política, Campos - RJ, Universidade Estadual do Norte Fluminense, ano 3, n. 5: 161-183, jul./dez.

TOLEDO, Caio Navarro de (Org.) (2005). Intelectuais e Política no Brasil: A Experiência do ISEB. Rio de Janeiro. Editora Revan. 
VASCONCELOS, Vasconcellos (1999). Darcy Ribeiro, o útero do povo. Folha de São Paulo.

WEFFORT, Francisco (2003). O Populismo na política Brasileira. São Paulo: Paz e Terra Editora.

ZARVOS, Guilherme (2007). Darcy Ribeiro (Coleção Encontros). Rio de Janeiro: Beco do Azougue Editora.

Artigo recebido em 22 de agosto de 2020.

Aprovado em 04 de dezembro de 2020.

DOI: $10.12957 /$ intellectus.2020.53942 